This is an author produced version of a paper published in Acta Obstetricia et Gynecologica Scandinavica. This paper has been peer-reviewed but does not include the final publisher proof-corrections or journal pagination.

Citation for the published paper:

Danerek, Margaretha and Udén, Giggi and Dykes, Anna-Karin

"Sympathetic responsibility in ethically difficult situations."

Acta Obstet Gynecol Scand. 2005 Dec;84(12):1164-71.

http://dx.doi.org/10.1111/j.0001-6349.2005.00697.x

Access to the published version may require journal subscription.

Published with permission from: Blackwell Synergy 


\section{Sympathetic Responsibility in Ethically Difficult Situations}

Margaretha Danerek, Giggi Udén and Anna-Karin Dykes

Faculty of Medicine

Department of Nursing

Lund University

Margaretha Danerek

Faculty of Medicine

Department of Nursing,

Lund University

Box 157,

22100 Lund

tel: +46 462221891

fax: +46 462221824

e-mail: margaretha.danerek@omv.lu.se

“There is much going on, much dynamic and many points of view". Co-operation and genuine communication with the midwives and other professionals are important issues while handling an ethically difficult situation to reach the best outcome for mother and infant. 


\section{Sympathetic Responsibility in Ethically Difficult Situations}

Background: Ethical issues arise in many obstetric situations and demand constant consideration by obstetricians. The aim of this study was to highlight the meaning of being in an ethically difficult situation as narrated by obstetricians.

Method: A descriptive design with a qualitative approach using a hermeneutic phenomenological method for analysis. Interviews were performed with fourteen obstetricians working in a Swedish hospital setting.

Results: The overriding theme was Sympathetic responsibility in decisions of critical importance for the mother and her infant. Five related themes; To proceed with a moral reasoning that leads to the choice of a possible solution; To balance one's own medical knowledge and moral insight with the needs and requests of the parents; To be aware of one's medical and moral responsibility in relation to the decision made; To experience the ability to take action and to make and carry out difficult and important decisions relating to the health of the mother and infant; and To reflect on a given situation in a manner leading to a rational acceptance of one's own conduct.

Conclusions: Sympathetic responsibility is the structure of the meaning of the obstetricians' lived experience, which means that the obstetricians with the help of their medical knowledge and their desire to support the mothers autonomy, do what is best for the mother and her infant. Implications include that an exchange of ethical thoughts and moral reasoning should lead to a higher degree of mutual understanding between colleagues and between the different professionals. Co-operation is important to achieve the best outcome for the mother and her infant.

Key words: ethics, obstetrics, obstetricians 


\section{Introduction}

Ethical issues arise in many obstetric situations and demand constant consideration by the obstetricians involved. Predominately there are two important issues, the moral status of the fetus and the autonomy of the woman. The moral status of the fetus includes the question of the beginning of life. When does the fetus become a human being during the pregnancy? From a conservative viewpoint a fertilised human ovum has been held to be the beginning of life. Other criteria for the moral status of the fetus are, "recognizably human", viability and by tradition at birth (1, p 46-58). The fact is also that today the infant may survive when born in gestation week 23, thanks to the medical and technical developments in perinatal and neonatal care. The medical responsibility shifts, at birth, from the obstetrician to the neonatologist (25). The other issue is the autonomy of the woman. When the mother has accepted the pregnancy she also takes on the responsibility for her fetus, which means an obligation to accept interventions. The mother has also the right to refuse interventions for her own part (57). Therefore, in these situations there arises the need to balance the wellbeing of the fetus and the autonomy of the woman (5). In a conflict between the rights and possible outcomes for the fetus versus the rights and possibilities of the mother, the obstetrician's moral obligation is to decide what to do in order to achieve the best outcome for both mother and infant (8-11). The main problem is that the choice could lead to morbidity in both short and long terms for the mother and the child (5). The ethical principal of respect for autonomy obligates the obstetrician to respect the integrity of the woman. The obstetrician can only put this respect for autonomy into practice by applying the process of informed choice (3). To highlight the experience of those who have found themselves in ethically difficult obstetric situations is important. It offers an opportunity to focus on the situations in the way the obstetricians experience them. 


\section{The ethically difficult obstetric situation}

The ethically difficult obstetric situations could e.g. be; that the pregnant woman refuses the treatment needed for her fetus $(10,19,20)$, a difficult decision in selective termination of one twin (21), the management of pregnancies complicated by fetal anomalies $(22,23)$, decisionmaking in prenatal diagnosis and termination of pregnancy (24) or a threat of very early delivery (5). According to the moral obligation to "do no harm" and respect for the woman's' autonomy the obstetrician has to make a choice what is the best for mother and fetus/infant. In meeting and working with other human beings who are in need of care and nursing, the moral obligation to help and do the best for them, can be seen in the perspective of nearness according to Lögstrup’s philosophy (25, p 50-55, p 145-150).

\section{Literature review}

Four studies about ethically difficult situations, performed in Norway and Sweden, in different units and with physicians, registered nurses and enrolled nurses, showed similar results, that there is a difference in moral reasoning between the professions. This was interpreted as being mainly connected to the different focus adopted within the professions nursing and medicine. Nurses were shown to be acting according to their own personal experience, giving and receiving care and the physicians to their knowledge gained through science and proven experience (12-15). In the findings it also appeared that the variation in moral reasoning did not depend on gender (15). To promote health is the overriding obligation for the physician (16). The hardest thing for the pediatricians were to know when treatment was in excess of what was of value to the infant and also to make decisions regarding life and death $(17,18)$. Studies about obstetricians' lived experience of ethically difficult situations have not, to our knowledge, been performed. Therefore it is important to highlight the obstetricians lived experience of these situations. 


\section{Aim}

The aim was to highlight the meaning of being in an ethically difficult obstetric situation as narrated by obstetricians

\section{Methods}

\section{Design and setting}

The study had a descriptive design and a qualitative research approach. As the focus was on the obstetricians' experience, interviews were performed and analyzed using a hermeneutic phenomenology method (26). The study took place in a university hospital in southern Sweden. The interviews were performed during January through May in the year 2000. Permission for the study was obtained from the Research Ethics Committee at the Faculty of Medicine, Lund University.

\section{Sample and data collection}

Inclusion criteria to participate in the study were for the informants to have been actively working as an obstetrician for at least two years at the department when the study took place. Fourteen obstetricians out of 20 chose to participate in the study. Reasons for not taking part were; being on parental leave, temporally working somewhere else at the time or excessive workload. Socio-demographic data was collected including gender, age and years of professional-experience as obstetricians and is shown in Table 1.

Insert table 1 here

The informants narrated their experience, moral reasoning, thoughts and feelings around an ethically difficult obstetric situation chosen by them. During the dialogue the interviewer intervened with questions such as "How did you think or feel about that?" Through the narrative method the informant was given occasion to reflect and to be aware of his or her 
thoughts and feelings during the lived experience (26, p 66-68; 27, p 14-20, 118). All the tape-recorded interviews were conducted at the department and took between 45-75 minutes. Some time was allowed, both before and after the interview in order to give the opportunity for further dialogue if desired. The first author (MD) performed all the interviews.

\section{Ethical consideration}

Initially the informants were first sent written information by post. After a week to allow for consideration regarding their interest or possibility to take part, the informants were contacted by telephone by the first author. Further information was offered at this time, and if the informants wished to participate a date and time was set for an interview. The informants were guaranteed confidentiality for themselves, their colleagues, other personnel and patients. All data was confidentially coded and stored safely. The informants were told that their participation was voluntary and that they could withdraw from the study at any time.

\section{Pre-understanding}

In a phenomenological approach (28, p 83-92) the author ought to "bracket” the knowledge about the phenomenon, in order to be able to study the phenomenon as it is shown. Van Manen (26, p 46-51), writes that even if the knowledge is forgotten or ignored the preunderstanding will affect the reflection. Therefore, it is better to make the pre-understanding explicit so there will be awareness about it (26). To be able to understand an ethical dilemma within the field of obstetrics it requires sufficient knowledge about the subject and its context. The first and the third author of this study have long experience in the field of obstetrics as midwives (30 years each) and are familiar with the context. This made it possible for the first author to meet the obstetricians during the interviews in a relevant way and for all authors to have fruitful analytic discussions. 


\section{Data analysis}

To analyze the data a hermeneutic phenomenological approach was chosen (26, p 77-109). This involves a process of reflective clarification in order to make the structure of meaning explicit. First, the interviews were transcribed word for word, and then the first author read each interview a number of times in order to gain an overall impression. Secondly, two of the authors (MD, A-KD) read the text line-by-line of each interview separately in order to isolate the significant aspects in the phenomenon. The meaning units were transformed into areas that said something significant about the phenomenon. Thirdly, asking questions relating to the areas and its belonging text, "what does it mean?” Followed by reflection in order to gain a deeper insight and understanding. Themes appeared and after reading all the themes from all the interviews, five themes finally emerged. Lastly, reflecting on the five themes produced an overriding theme, which is the structure of the meaning of the phenomenon. Through hermeneutic conversation the authors have discussed and reflected on the text and the themes in order to reach a deeper level in the analysis and to reach consensus (26).

\section{Results}

The overriding theme is Sympathetic responsibility in decisions of critical importance for the mother and her infant. The five related themes are: To proceed with a moral reasoning that leads to the choice of a possible solution; To balance one's own medical knowledge and moral insight with the needs and requests of the parents; To be aware of one's medical and moral responsibility in relation to the decision made; To experience the ability to take action and to make and carry out difficult and important decisions relating to the health of the mother and infant and; To reflect on a given situation in a manner leading to a rational acceptance of one’s own conduct. 


\section{The overriding theme}

\section{Sympathetic responsibility in decisions of critical importance for the mother and her infant.}

Sympathetic responsibility remains consistent throughout the process of decision-making. Having sympathy toward the mother and her unborn infant ensures that the obstetrician makes the effort to seek the best for their wellbeing. In an ethically difficult situation the obstetrician will go through a decision-making process. During this process, the obstetrician will make a choice followed by a decision and later reflect on the actions taken in order to move on to the next situation. As each situation that occurs is unique, there is no general solution as to how the obstetrician should proceed.

\section{Theme 1}

To proceed with a moral reasoning that leads to the choice of a possible solution

The ethical reasoning that guides the train of thought in each situation is "to do good" and "to do no harm”. The balance is between how far may the mother's health be endangered to give advantage of the fetus and what risks there are to the child's future health.

\footnotetext{
" So then I once again find myself in a situation that is extremely difficult to handle. She started to have contractions again that evening. Should I stimulate the contractions or just let her be or should I try to stop the contractions?” ( Int. N)

“.... If we let the mother give birth there is a great risk that the infant will be injured or will die. So there you stand! How active should we be? Often this is the difficult choice.” (Int. Y)

“ And there I think the ethical question is how far can we risk the mothers health. It was almost so that she was close to dying...should we risk her life for that of the infant?” (Int. G)
}

The respondents described that good communication with the staff is important to obtain their views and ideas about the woman's situation. It is important for the obstetrician to have 
genuine co-operation with the midwife. Staffs, who are not directly involved in an actual case, can sometimes disrupt the process if they have different opinions about how the mother should be treated.

\footnotetext{
“or in other cases that are difficult it is so that one consults ones colleagues and makes some sort of unanimous decision “ (Int. G)
}

" yes I felt that I had solved a great deal, myself and the midwife, it resulted in a very composed situation......and I think that the most difficult situation is when strong willed people pull in seventeen different directions. I know exactly in which direction I want to go but just at that point, I cannot stand and discuss and discuss and put forward arguments for every little thing. There is much going on, much dynamic and many points of view” (Int. A. )

\section{Theme 2}

To balance one's own medical knowledge and moral insight with the needs and requests of the parents.

The information the parent's request is given to them in a dialogue and this helps to increase their possibility to make an informed choice. Sometimes the obstetrician has a feeling of steering the parents as he/she has the knowledge. Where possible, consideration for the parent's desires and requests, together with the obstetrician's professional knowledge, form the basis for a course of treatment acceptable to all the parties.

\footnotetext{
"Then there is a lot of discussion, firstly on how things are to be done and one tries to accommodate the parents desires even if these may not steer the whole process “ (Int. S)
}

"as a general principle one had this discussion with her in an attempt to get her to
understand the risk to her own life compared with the risk of continuing the 
pregnancy. Despite understanding her situation, she wished to continue the pregnancy at all costs. The husband was more concerned with having a wife to take home, also, she was still at so early a stage that we could not save the infant if we were forced to let her give birth now" (Int. L.)

\section{Theme 3}

To know one's medical and moral responsibility in relation to the decision made.

The obstetrician is conscious of his or her ability and professional knowledge. The mother should not make critical medical decisions, medical decision-making is considered to be the right of the doctor. Although the parents should participate in the decision-making process.

\footnotetext{
"Yes and then I don't think that one can expect a patient to make a medical decision. We have the knowledge. Naturally, they should be able to make their voice heard and do this in collaboration with the doctor. They shall not have to make the decision on their own. It is we that have been trained and are paid to help the patient to make decisions of critical importance.”(Int. G.)
}

The regulations and guidelines governing health care in Sweden steer the doctor's possible course of action but are also experienced by them as supportive. In one case, an obstetrician experienced this support from a regulation requiring that the patient should be treated in accordance to her religion. In this case, the obstetrician had been refused permission by the woman to give her the treatment she required. A female obstetrician handled the case later, for the sake of the infant's health.

\footnotetext{
"I do not have a good ethical answer as to what one should do with a very sick infant whose life is at risk and lays in the womb and where I am not allowed access by the parents. I do not know. I cannot say anything more than that I must accept the patient's religious beliefs. In the situation where she refuses to allow me to access then I can do
} 
nothing. Then I must advise the parents concerning the patient's right to be treated in accordance with their beliefs and religion as described in the Swedish Health and Care regulations. It is stated explicitly.” (Int. C.)

\section{Theme 4}

To experience the ability to take action and to make and carry out difficult and important decisions for the health of the mother and infant.

Once the decision is made there is a single-mindedness to carry it out, however it can also be felt to be difficult, which can result in a state of uncertainty as the obstetricians does not know which is the optimal choice for the best outcome for the mother and her infant.

\footnotetext{
“..... in my naivism, I believed that it would be a rather simple procedure, but it was unbelievably difficult... yes, for me it wasn't so easy but at the same time I felt that I was quite decisive.” (Int V.)
}

"but I decided to do a very acute caesarian, which I did, and out comes a infant that is
somewhat poorly but regains very quickly, in fact.” (Int. F.)

\section{Theme 5}

To reflect on a given situation, in a manner leading to a rational acceptance of one's own conduct.

In general the obstetrician personally goes through the train of events many times, in order to work through the emotions and thoughts that occur, and further to achieve an acceptable standpoint which then crystallises from a strongly emotional field. Feelings of doubt and thoughts about the consequences of a decision being good or bad reoccur. This promotes a feeling of guilt among the obstetricians. Criticism and resistance from colleagues or from the mother is often experienced as emotionally straining, despite the fact that the obstetrician has made a professional effort. Feelings of dissatisfaction, tiredness and loneliness can be the result. 
"When one once again goes through the course of events for the thousandth time and think once again what, what would I have done differently?" (Int. Q.)

“....for a doctor then, when one feels that one has done one's absolute best and the outcome has been good, it is naturally a drawback to be reported and be questioned.. It is a difficult situation.... Emotionally it hasn’t felt so good, no it hasn’t...” (Int.F)

”Feelings of guilt are eating one up from within, so it requires some way to handle them..” (Int.A)

“my professional joy was heightened when things went so well. I have felt strong in what I have done, but it is purely professional..”(Int.F)

When the action was carried out it was felt to be the right one.

"I have never doubted that what I did was right.” (Int.V)

\section{Discussion}

Giorgi (29), Emden and Sandelowski $(30,31)$ describe how to validate qualitative analysis. The qualitative method can be discussed in the terms of truth-value, applicability, consistency and neutrality $(32,33)$.

The truth-value is evaluated against the criteria credibility. A qualitative study has credibility when it presents a description of a lived experience that other people, who have that experience, will recognize such as if the description was their own. To achieve the credibility the data is tested against relevant members of the data source group, "member checks" $(32,33)$. Two informants read the results of this study and recognize it as a possible 
description of being in an ethically difficult situation. The informants were all suitable participants in the study as they were obstetricians and were actively working at the clinic when the study took place.

Applicability is evaluated against the criteria fittingness. A qualitative study has fittingness when its findings "fit", the data where it is taken from. The findings are well grounded in the lived experience being studied and reflect the elements in the phenomenon $(32,33)$. In order to achieve fittingness in this study the authors show the relation between the themes and the interviews by quoting the interviews together with the themes in the findings. In accordance with Guba discussions were carried out between the authors to achieve consensus in the interpretation.

The consistency is evaluated against the criteria auditability. A qualitative study has auditability when other researchers clearly can follow the process that the investigator has used and reach the same or comparable but not contradictory conclusions by using the investigators data, perspective and situation (32,33). The authors, have in the method section, described all the steps taken during the research process and the analysis in order to achieve auditability.

Neutrality is evaluated against the criteria confirmability which is connected to the findings. It is achieved when truth-value, applicability and consistency are established. Neutrality means that the study is free from bias $(32,33)$. Bias in this study could be that the informants have narrated situations that took place many years ago and do not remember everything but what they have reflected on and learnt from the situation. The first author's experiences are that difficult situations remain clearly in the minds of the informants. The authors' difficulty has 
been to use the pre-understanding to get a nearness to the text and at the same time keep a distance to be able to describe and interpret the text in a meaningful way. It was beneficial that the first author has not known the informants or worked at the department. This has made it possible to avoid the situation that eventual conflicts in the workplace could colour the interpretation of the result. A hermeneutic discussion has taken place with the co-authors and at seminars and consensus in the analysis has been achieved (26).

Every ethically difficult obstetric situation that arises for the obstetrician is unique and the interviews reveal that there is no pattern for action to be followed; each situation requires its own solution. This may be compared with Lögstrup's (25 p 145-150) philosophy that states, what just that person we meet needs most, will show itself through the situation and its circumstances.

In this study it was revealed that the obstetricians have an all-embracing sympathetic responsibility that determines their choices, decisions and actions. Sympathetic responsibility is the basis of the relation between people and not at least that between patient and doctor. In meeting other people we meet the moral demand for responsibility. According to the interpretation of Lögstrup (25 p 145-150) the moral demand for responsibility is a mutual dependence, interdependence. Obstetricians feel their moral responsibility for the mothers and the mothers have a need of the care and treatment given by the obstetricians. This creates a mutual dependence that can be compared to Lögstrups' interdependence. However, obstetricians do not take over the responsibility from the mothers but rather try to involve them in the decision-making process. In similarity to Lögstrup (25, p 60) who states that the total responsibility for another person can never be taken over but the sense of responsibility should emphasize a consideration for another individual's autonomy (25). Within the process 
of offering sympathetic responsibility, obstetricians need to consider, make choices and then accept the consequences of their actions. At the decisive point, obstetricians found the power that enabled them to make decisions and to carry them through. Obstetricians bear the medical and moral responsibility and must therefore accept the consequences of their decisions. At the same time there is always a desire to make decisions that have positive consequences and will not hurt either the mother or her fetus. The principle to do good and not to cause harm occupies the obstetricians thoughts when choosing a course of action.

When obstetricians strive towards "good" consequences for both the mother and her fetus or infant, the problem of which of them to give priority is found to be difficult. That such difficult choices arise has been shown in different studies $(7,10,11)$. Although these conflicts can be difficult they are not the most commonly occurring. Often the obstetrician is in agreement with the parents concerning the method of treatment to be used (9). The principle of having respect for a patient's autonomy is well integrated into the activities of obstetricians.

Many situations that arose were based on a threat of early delivery or preterm birth in gestationweek 22+ - 28. The deciding factor whether or not to allow the pregnancy to continue is the omnipresent problem when considering the health of both the mother and her fetus. Obstetricians experience this situation, of having to choose, as being very difficult. The fear of causing a birth injury infant was clear. Moral stress was also present among caregivers who gave care to infants who were on "the border of viability" (34). Recently the Swedish National Board of Health and Welfare has presented a report about perinatal care in extreme preterm birth. This report includes a model for ethical analysis, which can be used in decisions concerning ethically difficult obstetric situations (35). 
This study has revealed that obstetricians have points of view concerning the special rights of the fetus, especially in those cases where the mother refuses intervention. Draper (6) and Pinkerton and Finnerty (7) discuss this point and if the mother has accepted the pregnancy she has thereby agreed to any necessary intervention for the sake of her fetus. A balance between the best for the fetus and the autonomy of the mother must exist in order to avoid conflict. $(2,3,8,10)$

By reasoning themselves to a comprehensible conclusion, obstetricians are able to accept the choices they have made and the course of action they have chosen. Their course of action is justified by converting negative emotions into something positive. Similar results were reached by Söderberg, Norberg and Gilje (36) who proposed that when a person has experienced a tragedy, while having sympathy and trust in life, feelings of doubt are converted to an active energy that gives the possibility to manage tragedy.

Communication between colleagues, parents and obstetricians is considered vital. This was shown also by Udén et al. (12) who concluded that communication between the groups of caregivers, concerning common ethical problems, would increase understanding for each other's reasoning in matters concerning morals. In Sörli, et al. $(17,18)$ it was proposed that communication between colleagues, around ethically difficult situations, was important.

\section{Conclusion}

By being aware of the unique points in a situation, by understanding the needs of the mother and her fetus, obstetricians will reach a solution. Sympathetic responsibility is the structure of 
the meaning of the obstetrician's lived experience and means that obstetricians with the help of their medical knowledge, and the will to consider the mother's autonomy, do what is best for the mother and her fetus. Emotional difficulties may be present but the obstetrician possesses the power to make the difficult decisions and act as required. Through sensible reasoning about the case, following the actions taken leads the obstetricians out of the field of emotion and enable them to move on.

\section{Implications}

An exchange of ethical thoughts and moral reasoning should lead to a higher degree of mutual understanding between colleagues, as well as between the different professionals, leading to better care for the mother and her fetus/infant. Forum or Balint groups (37-39) where the obstetricians could discuss their experiences and feelings concerning ethically difficult obstetric situations could be an empowering act. Interviewing midwives involved in ethically difficult obstetric situations, and comparing the results with the obstetricians, is an interesting study in order to achieve a deeper understanding for the different professions (in progress). Investigating parents' experiences of being in critical situations, such as a threat of early delivery and preterm birth, is also of interest in order to achieve a better understanding of the parents’ perspective (in progress). 


\section{Acknowledgements}

We are most grateful to the obstetricians for their participation in this study and to Geoffrey Dykes for revising the language. 


\section{References}

1. Steinbock B. Life before Birth. The Moral and Legal Status of Embryos and Fetuses. NewYork: Oxford University Press, 1992: 46-58.

2. Fleischman AR, Chervenak FA, McCullough LB. The physician's moral obligations to the pregnant woman, the fetus and the infant. Semin Perinatal 1998; 22: 184-188.

3. Chervenak FA, McCullough LB. Ethics in fetal medicine. Baillieres Clin Obstet and Gynaecol 1999; 13 (4): 491-502.

4. Pinkerton JV, Finnerty JJ, Lombardo PA, Rorty MV, Chapple H, Boyle RJ. Parental rights at birth of a near-viable infant: conflicting perspectives. Am J Obstet Gynecol 1997; 177 (2): 238-90.

5. Muraskas J, Marshall P, Tomich P, Myers T, Gianopoulos J, Thomasma D. Neonatal Viability in the 1990s: Held Hostage by Technology. Camb Q Healthc Ethics 1999; 8: 160172.

6. Draper H. Women, forced caesarians and antenatal responsibilities. J Med Ethics 1996; 22 (6): 327-33.

7. Pinkerton JV, Finnerty JJ. Resolving the clinical and ethical dilemma involved in fetalmaternal conflicts. Am J Obstet Gynecol 1996; 175:89-95.

8. Samsioe G, Aberg A. Ethical Issues in Obstetrics. Int J Ferti 1996; 41 (3): 284-287.

9. Chervenak FA, McCullough LB. Perinatal ethics: a practical method of analysis of obligations to mother and fetus. Obstet Gynecol 1985; 66(3): 442-6.

10. Strong C. Ethical conflicts between mother and fetus in obstetrics. Clin Perinatol 1987; 14(2): 313-28.

11. Iseminger KA, Lewis MA. Ethical challenges in treating mother and fetus when cancer complicates pregnancy. Obstet Gynegol Clin North Am (1998); 25 (2): 273-85. 
12. Udèn G, Norberg A, Lindseth A, Marhaug V. Ethical reasoning in nurses and physicians stories about care episodes. J Adv Nurs 1992; 17: 1028-1034.

13. Lindseth A, Marhaug V, Norberg A, Udèn G. Registered nurses' and physicians' reflections on their narratives about ethically difficult care. J AdvNurs 1994; 20: 245-250.

14. Udèn G, Norberg A, Norberg S. The stories of physicians, registered nurses and enrolled nurses about ethically difficult care episodes in surgical care. Scand J Caring Sci 1995; 9: 245-253.

15. Norberg A, Udèn G. Gender differences in moral reasoning among physicians, registered nurses and enrolled nurses engaged in geriatric and surgical care. Nurs Ethics 1995; 2 (3): 233-42.

16. Bremberg S, Nilstun T. Patients'autonomy and medical benefit: ethical reasoning among GPs. Fam Pract 2000; 17: 124-128.

17. Sörlie VM, Förde R, Lindseth A, Norberg A. Male physicians'narratives about being in ethically difficult care situations in pediatrics. Soc Sci Med 2001; 53 (5): 657-67.

18. Sörlie VM, Lindseth A, Udén G, Norberg A. Women physicians' narratives about being in ethically difficult care situations in pediatrics. Nurs Ethics 2000; 7: 47-62.

19. Adams SF, Mahowald MB, Gallgher J. Refusal of treatment during pregnancy. Clin Perinatol 2003; 30(1): 127-40.

20. Gyamfi C, Gyamfi M, Berkowitz R. Ethical and Medical Considerations in the Obstetric Care of a Jehovah's Witness. Obstet Gynecol 2003; 102(1): 173-80.

21. Holzman J. The Horns of the Dilemma Are Sharp. Camb Q Healthc Ethics Cambridge: University Press, 1999: 480-484.

22. Chervenak FA, McCullough LB, Skupski D, Chasen ST. Ethical issues in the management of pregnancy complicated by fetal anomalies. Obstet Gynecol Surv 2003; 58 (7): 473-83. 
23. Strong C. Fetal anomalies: ethical and legal considerations in screening for detection, and management. Clin Perinatol 2003; 30(1): 113-26.

24. Garel M, Gosme-Seguret S, Kaminski M, Cuttin M. Ethical decision-making in prenatal diagnosis and termination of pregnancy: a qualitative survey among physicians and midwives. Prenat Diagn 2003; 22: 811-817.

25. Lögstrup K.E. Det etiska kravet. [ The ethical demand].(in Swedish.) Göteborg: Daidalos, 1994: 50-55, 60, 145-150.

26. Van Manen M. Researching Lived Experience. Human Science for an Action Sensitive Pedagogy. Ontario: The Althouse press, 1997: 46-51, 66-68, 77-109.

27. Mishler E. Research interviewing: context and narrative. London: Harvard University, 1996:14-20,11.

28. Husserl E. Fenomenologins idé. [The concept of Phenomenology]. (in Swedish.) Göteborg: Daidalos, 1989: 83-92.

29. Giorgi A. Validity and reliability from a phenomenological perspective. In: Baker WJ, eds. Recent Trends in Theoretical Psychology. Proceedings of the Third Biennial Conference of the International Society for Theoretical Psychology, April 17-21, 1989. New York: Springer-Verlag, 1990: 167-176.

30. Emden C, Sandelowski M. The good, the bad and the relative, part one: Conception of goodness in qualitative research. Int J Nurs Pr 1998; 4: 206-212.

31. Emden C, Sandelowski M. The good, the bad and the relative, part two: Goodness and the criterion problem in qualitative research. Int J Nurs Pr 1998; 5: 2-7.

32. Guba E. Criteria for Assessing the Trustworthiness of Naturalistic Inquiries. ECTJ 1981; 29 ( 2): 75-91.

33. Sandelowski M. The problem of rigor qualitative research. Adv Nurs Sci 1986; 8 (3): 2737. 
34. Hefferman P, Heilig S. Giving "Moral Distress" a voice: Ethical Concerns among Neonatal Intensive Care Unit Personnel. Camb Q Healthc Ethics 1999; 8: 173-178.

35. Socialstyrelsen. Perinatalt omhändertagande vid extrem underburenhet. [the Swedish National Board of Health and Welfare. Perinatal Care in Extreme Preterm Birth.] (in Swedish.) Stockholm: Socialstyrelsen 2004.

36. Söderberg A, Norberg A, Gilje F. Meeting tragedy: interviews about situations of ethical difficulty in intensive care. Intensive Crit Care Nurs 1996; 12: 207-217.

37. Rudebeck CE. The doctor, the patient and the body. Scand J Prim Health Care 2000; 18 (1): 4-8.

38. Kulenovic M, Blazekovic-Milakovic S. Balint groups as a driving force of ego development. Coll Antropol 2000; 24(1): 103-8.

39. Clarke D, Coleman J. Balint groups. Examining the doctor- patient relationship. Aust Fam Physician 2002; 31 (1): 41-4. 
Table 1 Description of the informants

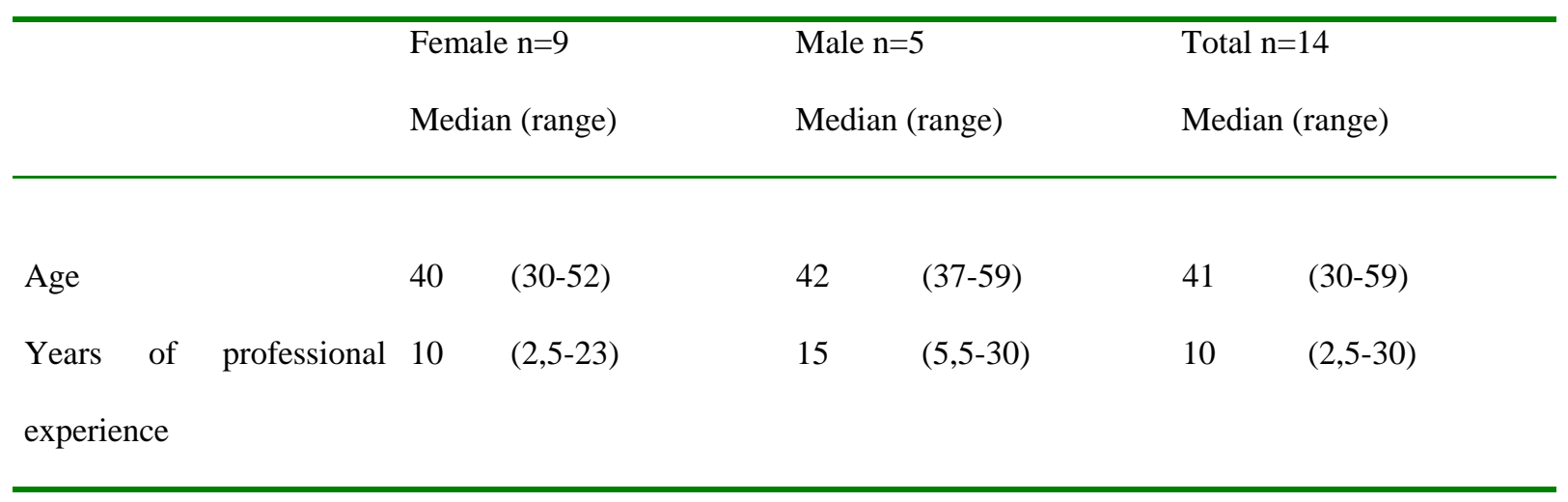

Table 2 Obstetric situations

\begin{tabular}{|c|c|c|c|c|c|}
\hline Preterm labor/birth & Gestation week & Term labor/birth & & $\begin{array}{l}\text { Gestation } \\
\text { week }\end{array}$ & Total \\
\hline Duplex/selective abortion & $22+$ & Rupture of membranes/fever & & 42 & \\
\hline Rupture of membranes /infection & $23+$ & Asphyxia & & 40 & \\
\hline Rupture of the membranes & $23+$ & Anomalies in pregnancy/birth & & 40 & \\
\hline \multicolumn{6}{|l|}{ /breech presentation } \\
\hline Triplex/diabetic & $23+$ & Emboli/asphyxia & & 40 & \\
\hline Toxicos/IVF & $24+$ & $\begin{array}{l}\text { Anomalies discovered } \\
\text { ultrasound }\end{array}$ & on & 40 & \\
\hline Ablatio & 24 & Ablatio & & 40 & \\
\hline Duplex/IVF/toxicos & 25 & Growth retardation/asphyxia & & 40 & \\
\hline Duplex/toxicos & 25 & & & & \\
\hline Duplex/toxicos & 25 & & & & \\
\hline Quadruplet & 28 & & & & \\
\hline Total & 10 & & & 7 & 17 \\
\hline
\end{tabular}


